\title{
COMPARATIVE STUDY ON REPRODUCTIVE PERFORMANCE OF BLACK AND YELLOW-FOOTED CHINESE INDIGENOUS GOOSE (SHITOU GOOSE) UNDER OFF- SEASON PRODUCTION CONDITIONS
}

\author{
Y. Guo ${ }^{1}$, Z. H. Zhao ${ }^{1}$, R. S. Huang ${ }^{1}$, X. Q. Chen ${ }^{1}$, L. X. Li $^{3,4}$, B. Balasubramanian ${ }^{2}$, R. M. Jia ${ }^{1 *}$ and W. C. Liu ${ }^{1 *}$ \\ ${ }^{1}$ Department of Animal Science, College of Coastal Agricultural Sciences, Guangdong Ocean University, Zhanjiang, \\ Guangdong 524088, P. R. China; ${ }^{2}$ Department of Food Science and Biotechnology, College of Life Science, Sejong \\ University, Seoul 05006, South Korea; ${ }^{3}$ Guangdong Lixing Agricultural Development Co., Ltd., Guangdong 524088, P. \\ R. China; ${ }^{4}$ Raoping Fubin Shitou goose original breeding base Co., Ltd., Guangdong 515700, P. R. China \\ *Correspondence: jiarm@gdou.edu.cn; liuwc@gdou.edu.cn
}

\begin{abstract}
The present study was conducted to compare the reproductive performance of black and yellow-footed Chinese indigenous goose, Shitou goose. A total of 890 two-year-old black-footed Shitou geese and 410 two-year-old yellowfooted Shitou geese were selected to carry out off-season feeding experiment to observe the eggs production, the law of laying eggs and the changes of body weight. The experiment time is one year. The results showed that the body weight of black-footed Shitou geese was less than that of yellow-footed Shitou geese, and the difference in body weight between male and female geese was very significant in February, April and June $(\mathrm{P}<0.01)$. After entering the breeding period, with the extension of the laying period, the body weight of female geese and the weight difference among breeds gradually decreased. However, the body weight of male geese did not change significantly during the breeding period. Meanwhile, the egg production of these two kinds of geese was not high. The number of qualified eggs produced by black-footed Shitou geese and yellow-footed Shitou geese was 32.46 and 28.66 respectively, and the corresponding breeding period was 301 days and 263 days, respectively. In addition, both species of geese have four egg production peaks during the breeding period. The laying time of black-footed Shitou geese was mainly concentrated in May, June, July, August and December and the monthly laying rates were $13.07 \%, 21.06 \%, 14.14 \%, 16.74 \%$ and $16.05 \%$, respectively. The average laying rate during the breeding period was $11.59 \%$. The laying time of yellow-footed Shitou geese was mainly concentrated in April, May, June, July and August and the monthly laying rates were $8.78 \%, 10.52 \%$, $15.76 \%, 7.08 \%$ and $6.20 \%$, respectively. The average laying rate during the breeding period was $10.60 \%$. Moreover, the weight changes of female geese of the two species of geese have the same law, that is, after entering the breeding period, the body weight gradually decreases with the extension of the laying period. However, the change of body weight of male geese during breeding period was not obvious. Taken together, the average egg production and egg laying rate of black-footed shitou geese are higher than that of yellow-footed Shitou geese. In addition, black-footed Shitou goose are more popular in the market in Leizhou Peninsula, so it is more suitable to raise black-foot Shitou goose in Zhanjiang area.
\end{abstract}

Keywords: Black-Footed Shitou geese; Yellow-Footed Shitou geese; egg production performance; weight change; offseason.

https://doi.org/10.36899/JAPS.2021.2.0252

Published online October 03,2020

\section{INTRODUCTION}

Shitou goose is the only large goose species in China, and it is also one of the three large goose species in the world, which is known as "the goose king of the world" (Wang, 2007; Jia et al., 2011). It is now one of the key protected species of national poultry breed resources in China ( $\mathrm{Li}$ and Lin, 2003). Shitou goose originated in Raoping County, Guangdong Province, and it is now mainly distributed in Chaoshan area (Ye and Zhong, 2005). Because the authentic Chaoshan Shitou goose has gray feathers and yellow flippers, it is also called yellowfooted Shitou goose. Black-footed Shitou goose is a large species of geese from Leizhou Peninsula, its appearance is very similar to Chaoshan Shitou goose, but the feathers are dark gray, flippers are black. There is no information on the formation history of black-footed Shitou goose. In the process of the formation of varieties, the pattern of genetic differentiation among varieties is closely related to the geographical distribution (Tu et al., 2006; Wang et al., 2005). It is speculated that the black-footed Shitou goose may be formed by differentiation from different regions (Arnoux et al., 2014), or it may be crossbred by the yellow-footed Shitou goose with local geese or Guangxi goose, which is similar to Hepu goose (Liang, 2001). Black-footed Shitou goose is increasingly favored by consumers of Zhanjiang because of their good meat quality and high economic value, it's proportion in the 
Chinese meat market is also growing. However, to the best of our knowledge, until now, there was no study on the reproductive performance or egg laying performance of this black-footed shitou goose, also, no data has been reported about the comparison of reproductive performance between black and yellow-footed Shitou goose under off-season breeding. Although the blackfooted Shitou goose is very similar to the yellow-footed Shitou goose, there are still some differences between them. Hence, the aim of the present study was to compare the difference of egg laying performance between blackfooted Shitou goose and yellow-footed Shitou goose under off-season production conditions, as well as the law of laying eggs and the change of body weight. The findings could provide the foundation for raising these two breeds of goose in Zhanjiang, Guangdong Province, China.

\section{MATERIALS AND METHODS}

All experimental protocols describing the management and care of animals were reviewed and approved by the Animal Care and Use Committee of Guangdong Ocean University, Zhanjiang, Guangdong, P. R. China.

Birds and Experimental Procedures: A total of 890 two-year-old black-footed Shitou geese (140 male geese and 750 female geese) from Leizhou Peninsula and 410 two-year-old native yellow-footed Shitou geese (62 male geese and 348 female geese) from Chaoshan, respectively. All birds were raised in geese house with egg nests full of straw, and the front of the geese house is equipped with a wide enough playground and a clean pool. Keep the playground dry and permeable and keep the water clean and hygienic. Geese houses were required air circulation, dry and moisture proof, economical and durable. Therefore, longitudinal ventilation is adopted in the house, and wet curtain cooling facilities are used at the air inlet of negative pressure ventilation. The feeding density is not more than 2.5 per square meter. Geese are subcutaneously or intramuscularly injected with Newcastle attenuated vaccine, avian influenza H5N1 inactivated vaccine, geese paramyxovirus inactivated vaccine and duck plague vaccine. The laying period is mainly fed with the full-price compound feed provided by Shenchang Agricultural and Animal Husbandry Professional Cooperative, supplemented by green feed such as ryegrass, chicory and so on. Fed regularly and quantitatively, and the geese have free access to food and water. After laying eggs last year, the breeding geese with good physique, excellent laying performance and weak nesting were selected for forced molting, and the nutritional level of the diet during the laying period was adjusted in time. The main breeding geese in the rest period are grazing.
Sampling and Measurements: The determination of productive parameters based on our earlier studies (Liu et al., 2019; Guo et al., 2020; Liu et al., 2020), briefly, during the experiment, all the eggs were collected and recorded. Remove abnormal eggs such as broken eggs, soft shell eggs, double-yolked eggs, etc. After each collection, it was fumigated with formaldehyde and stored in a seed egg bank at $18-20^{\circ} \mathrm{C}$ for no more than one week. The geese are numbered, and the male and female geese are weighed and recorded on a fixed date each month. The weight changes of geese were observed during a reproductive cycle. Calculate monthly weight gain, relative growth rate, egg laying rate, average egg laying number and egg laying ratio.

Statistical Analysis: The data were analyzed by using SPSS software. Data were expressed as means \pm standard deviation. Difference among treatment means were tested by using LSD. $\mathrm{P}<0.05$ was considered to be statistically significant.

\section{RESULTS AND DISCUSSION}

Body weight: The difference in weight between blackfooted Shitou geese and yellow-footed Shitou geese as shown in Table 1 and 2. No matter male geese or female geese, the body weight of black-footed Shitou geese is less than that of yellow-footed Shitou geese. The difference in body weight between the two geese was extremely significant in February, April and June $(\mathrm{P}<$ 0.01). These differences may be due to the long-term regional differentiation between the black-footed Shitou geese and the yellow-footed Shitou geese, resulting in the isolation of species, and then evolved into two species with obvious differences (Szwaczkowski et al., 2007). It may also be because of the black-footed Shitou geese is the result of a new breed of yellow-footed Shitou geese crossed with local or Guangxi geese. According to the results of the investigation on the breed resources of Shitou geese ( $\mathrm{Li}$ and Lin, 2003), the body weight of black-footed Shitou geese and yellow-footed shitou geese in this experiment is lower than the standard body weight of Shitou geese in general. This experiment showed that the change law of the body weight of male geese is not obvious, in addition to breed reasons, it may also be related to season, climate, and light, but the specific reasons have not been deeply studied in this experiment, it warrants further investigations. Meanwhile, there is a negative correlation between the body weight of female geese and the extension of laying period, which may be because of the loss of body weight due to the consumption of energy stored in the body by laying eggs (Wang et al., 2008).

In addition, due to the off-season breeding scheme adopted in this experiment, the geese were closed from January to April, and after a period of restricted 
feeding for about a month, theoretically, the body weight of both male and female Shitou geese will be lower than that at the end of last year (Qi, 2013). However, after feed restriction and artificial forced molting (Ma et al., 2000), the geese began to be replenished. Therefore, when weighed in April, the weights of both the black-footed Shitou male geese and the yellow-footed Shitou geese were higher than those in February. As for the blackfooted Shitou geese and the yellow-footed Shitou male geese, although they decreased slightly from February to April, the decline was small and basically stable, so the effects of feed restriction, plucking, supplementary feeding and other factors in the off-season production process could not be ruled out. In addition, the process of off-season production may cause adverse effects such as pore damage and decreased immunity of breeding geese. However, because the main purpose of this experiment is to study and compare the body weight changes of blackfooted and yellow-footed Shitou geese during breeding period, so this experiment did not make a specific analysis on the details and effects of off-season production conditions.

Laying performance: As shown in Table 3 and 4, the laying period, average laying number and average laying rate of black-footed Shitou geese are 301 days, 32.46 and $11.59 \%$ respectively, while the corresponding yellowfooted Shitou geese are 263 days, 28.66 and 10.60\%, respectively. According to the general situation of Tang et al. (2011) on the production performance of Shitou geese, it can be found that the average egg number and average laying rate of black-footed Shitou geese and yellowfooted Shitou geese are within the standard range. However, from the comparison of the data between the black-footed Shitou geese and the yellow-footed Shitou geese, it is obvious that the laying period of the blackfooted Shitou geese is longer, and the average number of eggs and the average laying rate are higher than those of the yellow-footed Shitou geese. These differences may not only be related to the breed of geese, the amount of feed, the specific ecological environment, the evenness of the flock and other factors, but also because of the blackfooted Shitou geese is native to Zhanjiang, while the yellow-footed Shitou geese are introduced from Chaoshan area. Although it is in the same Guangdong region, one in eastern Guangdong and the other in western Guangdong, the longitude and latitude are slightly different, and the labor of riding is a strong stress for yellow-footed Shitou geese (Ge et al., 2009), resulting in differences in geese in different regions. Therefore, although the yellow-footed Shitou geese are better than the black-footed Shitou geese in terms of weight and the number of eggs laid, the laying rate is lower than that of the black-footed Shitou geese. From the experimental results, it can be seen that the egg laying rules between the two varieties are relatively close, which may be due to the use of off-season production technology in this experiment. it may also be linked with the fact that both black-footed Shitou geese and yellow-footed Shitou geese are the offspring of Hong geese and belong to the same species. And in this experiment, the two geese live in the same ecological environment and geographical location in the Leizhou Peninsula of Zhanjiang (Biesiada et al., 2015), which may be one of the reasons why the laying rules of the two geese are similar.

Additionally, Guo et al. (2015) have reported that the breed and size of breeding geese would affect their egg production. The annual egg production of Shitou geese is only 28-35 eggs, Lande Geese 35 eggs, Rhine Geese 50 eggs 60, Zi Geese 100-140 eggs, up to 180. Among these geese, the Shitou geese has the largest body size, but the laying rate is the lowest. Combined with this experiment, it is not difficult to find that the body weight of the yellow-footed Shitou geese is larger than that of the black foot lion head geese, and the laying rate is lower than that of the black foot lion head geese, which is also in line with the rules of these studies.

Table 1. Comparison of male and female body weight between black-footed Shitou geese and yellow-footed Shitou geese.

\begin{tabular}{ccccc}
\hline \multirow{2}{*}{ Month } & \multicolumn{2}{c}{ Male } & \multicolumn{2}{c}{ Female } \\
\cline { 2 - 5 } & Yellow-footed (kg) & Black-footed (kg) & Yellow-footed (kg) & Black-footed (kg) \\
\hline 2 & $8.78 \pm 1.01^{\mathrm{A}}$ & $6.94 \pm 0.60^{\mathrm{C}}$ & $6.80 \pm 0.68^{\mathrm{a}}$ & $6.37 \pm 0.98^{\mathrm{c}}$ \\
4 & $7.91 \pm 0.81^{\mathrm{A}}$ & $7.26 \pm 0.79^{\mathrm{C}}$ & $7.21 \pm 0.58^{\mathrm{a}}$ & $6.36 \pm 0.55^{\mathrm{c}}$ \\
6 & $8.41 \pm 0.72^{\mathrm{A}}$ & $7.04 \pm 0.55^{\mathrm{C}}$ & $6.99 \pm 1.02^{\mathrm{a}}$ & $6.36 \pm 0.74^{\mathrm{c}}$ \\
8 & $8.10 \pm 0.59^{\mathrm{A}}$ & $7.10 \pm 0.75^{\mathrm{C}}$ & $6.80 \pm 0.67^{\mathrm{a}}$ & $6.35 \pm 0.79^{\mathrm{b}}$ \\
10 & $7.75 \pm 0.98^{\mathrm{A}}$ & $7.34 \pm 0.52^{\mathrm{A}}$ & $6.69 \pm 0.75^{\mathrm{a}}$ & $6.18 \pm 0.66^{\mathrm{c}}$ \\
12 & $7.98 \pm 0.80^{\mathrm{A}}$ & $7.24 \pm 0.48^{\mathrm{B}}$ & $6.51 \pm 0.92^{\mathrm{a}}$ & $6.12 \pm 0.55^{\mathrm{a}}$ \\
\hline
\end{tabular}

Note: The difference of shoulder mark capital letter interval between male geese is extremely significant $(\mathrm{P}<0.01)$, the difference of adjacent letters is significant $(\mathrm{P}<0.05)$, and the difference of the same letter is not significant; the difference of shoulder mark lowercase letter interval between female geese is extremely significant $(\mathrm{P}<0.01)$, the difference of adjacent letters is significant $(\mathrm{P}<0.05)$, and the difference of the same letter is not significant.

Therefore, through the comparative analysis of the average number of eggs and the average laying rate in the laying performance of the two goose breeds, it reflects the adaptability of the reproductive performance 
of the black-footed Shitou goose and the yellow-footed Shitou goose in Zhanjiang area. It is not difficult to see that the reproductive performance of the original black- footed Shitou goose in Zhanjiang is better than that of the yellow-footed Shitou goose introduced from Chaoshan area.

Table 2. Body weight changes of black-footed Shitou geese and yellow-footed Shitou geese during off-season production.

\begin{tabular}{|c|c|c|c|c|c|c|c|c|c|c|c|c|}
\hline \multirow{3}{*}{ Month } & \multicolumn{4}{|c|}{ Weight（kg） } & \multicolumn{4}{|c|}{$\begin{array}{l}\text { Monthly weight gain } \\
\text { (kg/2 months) }\end{array}$} & \multicolumn{4}{|c|}{ Relative growth rate $(\%)$} \\
\hline & \multicolumn{2}{|c|}{ Black-footed } & \multicolumn{2}{|c|}{ Yellow-footed } & \multicolumn{2}{|c|}{ Black-footed } & \multicolumn{2}{|c|}{ Yellow-footed } & \multicolumn{2}{|c|}{ Black-footed } & \multicolumn{2}{|c|}{ Yellow-footed } \\
\hline & male & Female & male & female & male & female & male & female & male & female & male & female \\
\hline 2 & 6.94 & 6.37 & 8.78 & 6.80 & & & & & & & & \\
\hline 4 & 7.26 & 6.36 & 7.91 & 7.21 & 0.32 & 0.00 & -0.87 & 0.41 & 4.60 & -0.07 & -9.92 & 6.08 \\
\hline 6 & 7.04 & 6.36 & 8.41 & 6.99 & -0.23 & -0.01 & 0.50 & -0.22 & -3.10 & -0.12 & 6.30 & -3.05 \\
\hline 8 & 7.10 & 6.35 & 8.00 & 6.80 & 0.06 & -0.01 & -0.40 & -0.19 & 0.89 & -0.14 & -4.82 & -2.70 \\
\hline 10 & 7.43 & 6.18 & 7.75 & 6.69 & 0.33 & -0.17 & -0.25 & -0.11 & 4.65 & -2.62 & -3.09 & -1.62 \\
\hline 12 & 7.24 & 6.12 & 7.98 & 6.51 & -0.19 & -0.06 & 0.23 & -0.18 & -2.56 & -0.97 & 2.94 & -2.74 \\
\hline Average & 7.17 & 6.29 & 8.14 & 6.83 & 0.06 & -0.05 & -0.16 & -0.06 & 0.82 & -0.81 & -2.00 & -0.89 \\
\hline $\mathrm{Sd}$ & 0.16 & 0.10 & 0.35 & 0.22 & 0.24 & 0.06 & 0.48 & 0.24 & 3.34 & 0.98 & 5.74 & 3.48 \\
\hline $\mathrm{CV}$ & 0.02 & 0.02 & 0.04 & 0.03 & 4.01 & -1.25 & -3.02 & -4.12 & 4.07 & -1.21 & -2.87 & -3.91 \\
\hline
\end{tabular}

Table 3. Egg laying of black-footed Shitou geese.

\begin{tabular}{ccccccccccc}
\hline Month & $\mathbf{4}$ & $\mathbf{5}$ & $\mathbf{6}$ & $\mathbf{7}$ & $\mathbf{8}$ & $\mathbf{9}$ & $\mathbf{1 0}$ & $\mathbf{1 1}$ & $\mathbf{1 2}$ & Total \\
\hline Number of eggs laid & 416 & 3038 & 4739 & 3270 & 3788 & 1837 & 433 & 3486 & 2491 & 23498 \\
Coulan goose & 750 & 750 & 750 & 746 & 730 & 728 & 728 & 724 & 724 & 724 \\
Average number of eggs laid & 0.56 & 4.05 & 6.32 & 4.38 & 5.19 & 2.52 & 0.60 & 4.82 & 3.44 & 32.46 \\
Laying rate (\%) & 2.22 & 13.07 & 21.06 & 14.14 & 16.74 & 8.41 & 1.92 & 7.71 & 16.05 & 11.59 \\
Egg production ratio(\%) & 1.83 & 13.39 & 20.89 & 14.42 & 16.70 & 8.10 & 1.91 & 7.38 & 15.37 & 100 \\
\hline
\end{tabular}

Table 4. Egg laying of yellow-footed Shitou geese.

\begin{tabular}{lcccccccccc}
\hline \multicolumn{1}{c}{ Month } & $\mathbf{4}$ & $\mathbf{5}$ & $\mathbf{6}$ & $\mathbf{7}$ & $\mathbf{8}$ & $\mathbf{9}$ & $\mathbf{1 0}$ & $\mathbf{1 1}$ & $\mathbf{1 2}$ & Total \\
\hline Number of eggs laid & 917 & 1135 & 1645 & 724 & 613 & 184 & 420 & 344 & 37 & 6019 \\
Coulan goose & 348 & 348 & 348 & 330 & 319 & 301 & 289 & 256 & 210 & 210 \\
Average number of eggs laid & 2.64 & 3.26 & 4.73 & 2.19 & 1.92 & 0.61 & 1.45 & 1.34 & 0.18 & 28.66 \\
Laying rate (\%) & 8.78 & 10.52 & 15.76 & 7.08 & 6.20 & 2.04 & 4.69 & 4.48 & 0.93 & 10.6 \\
Egg production ratio (\%) & 15.24 & 18.86 & 27.33 & 12.03 & 10.18 & 3.06 & 6.98 & 5.72 & 0.61 & 100.00 \\
\hline
\end{tabular}

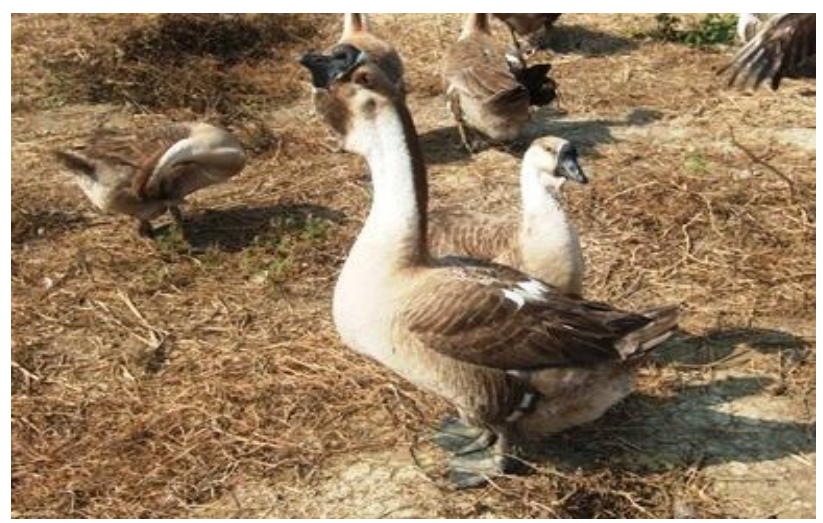

Black-footed Shitou goose

Fig. 1. The illustration of black and yellow-footed Shitou goose

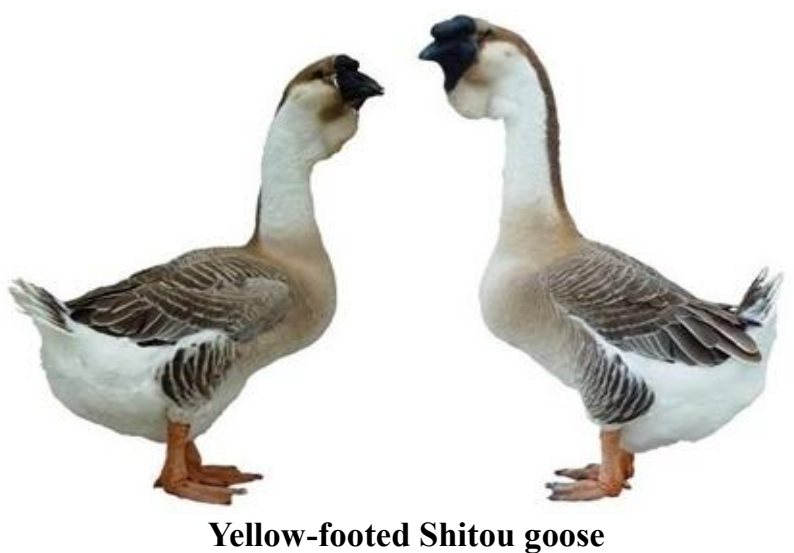


Conclusion: To conclusion, in this experiment, the site of the experiment is Zhanjiang, where the average egg number and average laying rate of black-footed Shitou geese are higher than those of yellow-footed shitou geese, and the black-footed Shitou goose are more popular in Leizhou area. Therefore, it is more suitable to use offseason technology to raise black-footed Shitou goose in Leizhou area.

Authors' Contribution: RM Jia conceived and designed the study. ZH Zhao and B Balasubramanian helped in preparation of the manuscript. RS Huang, XQ Chen, LX $\mathrm{Li}$ and $\mathrm{Y}$ Guo performed experimental work, Y Guo and WC Liu analyzed the data and wrote the article, WC Liu and $\mathrm{ZH}$ Zhao revised the manuscript.

Acknowledgments: This research was funded by Innovation team of modern agricultural industrial technology system in Guangdong Province (2019KJ137); Chaozhou science and technology plan project (2017N05); Variety selection and healthy breeding of Shitou goose (B15337); Raoping County Science and technology plan project (RAOJIN [2018] No. 43).

Conflicts of Interest: The authors declare they have no conflict of interest.

\section{REFERENCES}

Arnoux, E., C. Eraud and N. Navarro (2014). Morphology and genetics reveal an intriguing pattern of differentiation at a very small geographic scale in a bird species, the forest thrush Turdus lherminieri. Heredity. 113(6):514525.

Biesiada-Drzazga, B., D. Banaszewska, A. Koncerewicz, A. Jóźwik and J. Horbańczuk (2015). Examination of changes in selected external and internal egg traits during the goose laying season and their effect on gosling hatching results. Poult. Sci. 79(19):41-43.

Ge, R.L., Y.J. Sun and M.X. Li (2009). Introduction technology of goose breeds. Animal Husbandry and Feed Science. 30(11):181-184.

Guo, W.K., Z.F. Chen and J.M. Zhou (2015). Analysis of factors affecting egg production of breeder goose. J. Heilongjiang Bayi Agricultural Reclamation University. (03):44-51.

Guo, Y., Z.H. Zhao, Z.Y. Pan, L.L. An, B. Balasubramanian, and W.C. Liu (2020). New insights into the role of dietary marine-derived polysaccharides on productive performance, egg quality, antioxidant capacity, and jejunal morphology in late-phase laying hens. Poult. Sci. 99:2100-2107.

Jia, R.M., H.Y. Wu, Y. Liu, and L. Zhang (2011). Cloning and prokaryotic expression of PRL gene in Shitou goose. Acta Veterinaria et Zootechnica Sinica. 42(3):343-348.

Li, Z.P. and Q.T. Lin (2003). Investigation on breed resources of Shitou goose. China Poultry Industry Guide. (04):36-37.

Liang, H.T. (2001). Preliminary report on the effect of Hepu goose crossbred Sichuan White goose in Nanning. Guangxi Animal Husbandry and Veterinarian. 17(2):5-9.

Liu, W., Y. Yuan, C. Sun, B. Balasubramanian, Z. Zhao, and L. An (2019). Effects of dietary betaine on growth performance, digestive function, carcass traits, and meat quality in indigenous yellowfeathered broilers under long-term heat stress. Animals 9(8):506.

Liu, W.C., S.H. Zhou, B. Balasubramanian, F.Y. Zeng, C.B. Sun, and H.Y. Pang (2020). Dietary seaweed (Enteromorpha) polysaccharides improves growth performance involved in regulation of immune responses, intestinal morphology and microbial community in banana shrimp Fenneropenaeus merguiensis. Fish Shellfish Immun. 104:202-212.

Ma, X., Z.H. Yue and S.Z. Jin (2000). Research and application of forced molting technology. China Poultry Industry Guide. (23):23-24.

Qi, H.J. (2013). Feeding and management of goose during laying period and off-laying period. Aquaculture Technical Consultant. (12):22-22.

Szwaczkowski, T., S. Wezyk and E. StanisławskaBarczak (2007). Genetic variability of body weight in two goose strains under long-term selection. J. Applied Genetics. 48(3):253-260.

Tang, X.G., X.Y. Peng and J.Y. Sun (2011). General situation of study on production performance of Shitou goose. Guangdong Animal Husbandry and Veterinary Science and Technology. 36(4):34.

Tu, Y.J., K.W. Chen and S.J. Zhang (2006). Genetic Diversity of 14 Indigenous Grey goose Breeds in China Based on Microsatellite Markers. Asian Austral. J. Anim. Sci. 19(1):1-6.

Wang, B.W., W.H. GE and M.G. Zhang (2008). Study on out-of-season breeding technique of meat breeder goose. Chin. Poult. 30(3):13-16.

Wang, J.W., X.P. Qiu and F.T. Zeng (2005). Study on genetic differentiation of main domestic goose breeds in China. JGG. 32(10):1053-1059.

Wang, X.G. (2007). Several fine breeds of poultry. Scientific planting and breeding. (08):53.

Ye, C.H. and R.C. Zhong (2005). Studies on Growth Model of Shitou Goose. J. Shihezi University (Natural Sci.). (6):694-697. 